\title{
Новые данные о возрасте и гетерогенности Контайской интрузии (Полярная Сибирь)
}

\author{
Зайцев В.А. ${ }^{1}$, Елизаров Д.В. ${ }^{2}$ \\ ${ }^{1}$ ГЕОХИ РАН, Москва, alkaline@geokhi.ru \\ ${ }^{2}$ Геологический институт КНЦ РАН, Anamumbl, elizarov@geoksc.apatity.ru
}

Аннотация. Контайская расслоенная интрузия - относительно новый представитель магматизма Полярной Сибири, обнаруженный между наиболее детально изученными районами: Норильским и МаймечаКотуйским. В статье приводятся новые $\mathrm{Rb} / \mathrm{Sr}$ и $\mathrm{Sm} / \mathrm{Nd}$ данные для пород интрузии. $\mathrm{Rb} / \mathrm{Sr}$ оценка возраста по биотиту $244.9 \pm 2.8$ млн. лет, соответствует окончанию первого пульса внедрения Сибирских трапповых базальтов, совпадает с возрастом меймечитов и временем отжига треков в апатите Гулинской интрузии. $\mathrm{Sr}$ и $\mathrm{Nd}$ изотопная систематика для этого возраста демонстрирует гетерогенность как на уровне пород, так и на уровне минералов, что интерпретируется как следствие внедрения магмы, контаминированной ксенокристаллами, которые не были полностью переуравновешены.

Ключевые слова: Сибирский плюм, Контайская интрузия, возраст, $\mathrm{Sr}-\mathrm{Nd}$ изотопная систематика.

\section{The new data on the age and isotope heterogeneities of Kontay intrusion (Polar Siberia)}

\author{
Zaitsev V.A. ${ }^{1}$, Elizarov D.V. ${ }^{2}$ \\ ${ }^{1}$ Vernadsky Institute of Geochemistry and Analyticlcal Chemistry RAS, Moscow, alkaline@geokhi.ru \\ ${ }^{2}$ Geological Institute of Kola Scientific Center RAS, Apatity, elizarov@geoksc.apatity.ru
}

\begin{abstract}
The Konay intrusion, located between Maimecha-Kotuy and Norilsk areas is one of the least well understand layered intrusion of Siberian plume. We present new $\mathrm{Sr}$ and $\mathrm{Nd}$ isotopic data for the rocks. The biotite $\mathrm{Rb} /$ $\mathrm{Sr}$ age of $244.9 \pm 2.8 \mathrm{Ma}$ in accordance with zircone $\mathrm{U}-\mathrm{Pb}$ data corresponds to the age meimechites and apatite fission track age of Guli pluton and the terminal part of first pulse of Sinerian flood basalt event . $\varepsilon_{\mathrm{t}} \mathrm{Nd}$ and $\left({ }^{87} \mathrm{Sr} r{ }^{86} \mathrm{Sr}\right)_{\mathrm{i}}$ data demonstrate isotope heterogeneity both on the rock and the mineral scale. We thick that magma of Konay intrusion was contaminated by previously formed xenocrystals, that wasn't fully re-equilibrated with melt.
\end{abstract}

Key words: Siberian plume, Kontay intrusion, age, Sr-Nd isotope systematic.

\section{Введение}

Сибирский плюм - один из наиболее ярко проявленных случаев появления плюмовой геодинамики нашей планеты, имевший место на рубеже перми и триаса. С ним связана одна из крупнейших магматических провинций, породы которой распространены от Урала до Якутии и от Таймыра до верховьев Ангары. Наиболее подробно этот магматизм изучен в северной части, где расположена Норильская группа месторождений и Маймеча-Котуйская щелочная провинция. Относительно недавно схема магматизма Полярной Сибири была дополнена монцогаббро-монцодиоритовым Контайским комплексом (Липенков и др., 2018), единственным известным представителем которого является Контайская интрузия, но его возраст и роль в магматизме региона оставались дискуссионными.

Возраст комплекса ранее был определён $\mathrm{Rb}-\mathrm{Sr}$ изохроной по серии пород как нижнепалео-

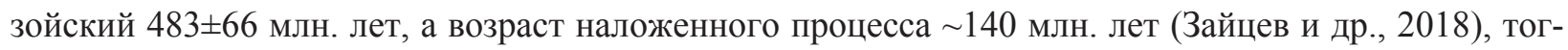
да как полученные датировки по цирконам, выделенным из пород интрузии: $248.5 \pm 2.6$ млн. лет, $246.5 \pm 2.6$ млн. лет, $249.9 \pm 5.2$ млн. лет соответствуют раннему триасу (Липенков и др., 2018).

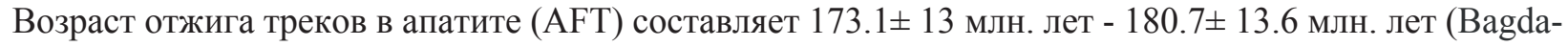
saryan et al., 2020).

Обе изотопные версии датировки проблематичны. Первая - потому, что в районе отсутствуют магматические проявления, с которыми она могла бы быть соотнесена, хотя имеются находки цирконов сходного возраста, кроме того, после появления AFT-датировок апатита геологический смысл датировки так называемого «наложенного процесса» выглядит неясным. Вторая - потому, 
что датированные цирконы, вероятно, имеют вторичную природу. (Зайцев, Елизаров, 2019). В связи с этим были проведены дополнительные изотопные исследования Rb-Sr и Sm-Nd изотопных систем.

\section{Геологическая позиция}

Контайская интрузия $\left(70^{\circ} 49^{\prime}\right.$ сш.ш. $10^{\circ} 09^{\prime}$ в.д.), расположена на западной границе МаймечаКотуйской провинции (примерно 30 км к западу-юго-западу от Гулинского массива). Интерпретация геофизических данных говорит о лакколитообразной форме интрузии, с горизонтальными размерами порядка $8 \times 15$ км и мощностью около 2.5 км (Кушнир, 2005) Массив рассечён серией даек мелкокристалических палагонитовых долеритов мощностью от первых десятков сантиметров до 15 м. (Липенков и др., 2018). Вторичные преобразования пород массива отвечали условиям цеолитовой, пренит-пумпелиитовой и зеленосланцевой фаций (Зайцев и др., 2018).

Комплексное минералого-петролого-геохимическое изучение пород показало, что породы интрузии образуют единую серию, демонстрируя дифференциацию от богатых магнетитом ортопироксен-содержащих биотитовых габбро и габброноритов до кварцевых монцонитов, за исключением самой верхней части разреза, сложенной гранодиоритами (рис. 1). Она существенно отличается, как от расположенных восточнее ийолит-карбонатитовых интрузий Маймеча-Котуйской провинции, так и от интрузивов Норильского района. При этом породы интрузии заметно менее магнезиальны, чем развитые в районе вулканиты (Зайцев и др, 2018).

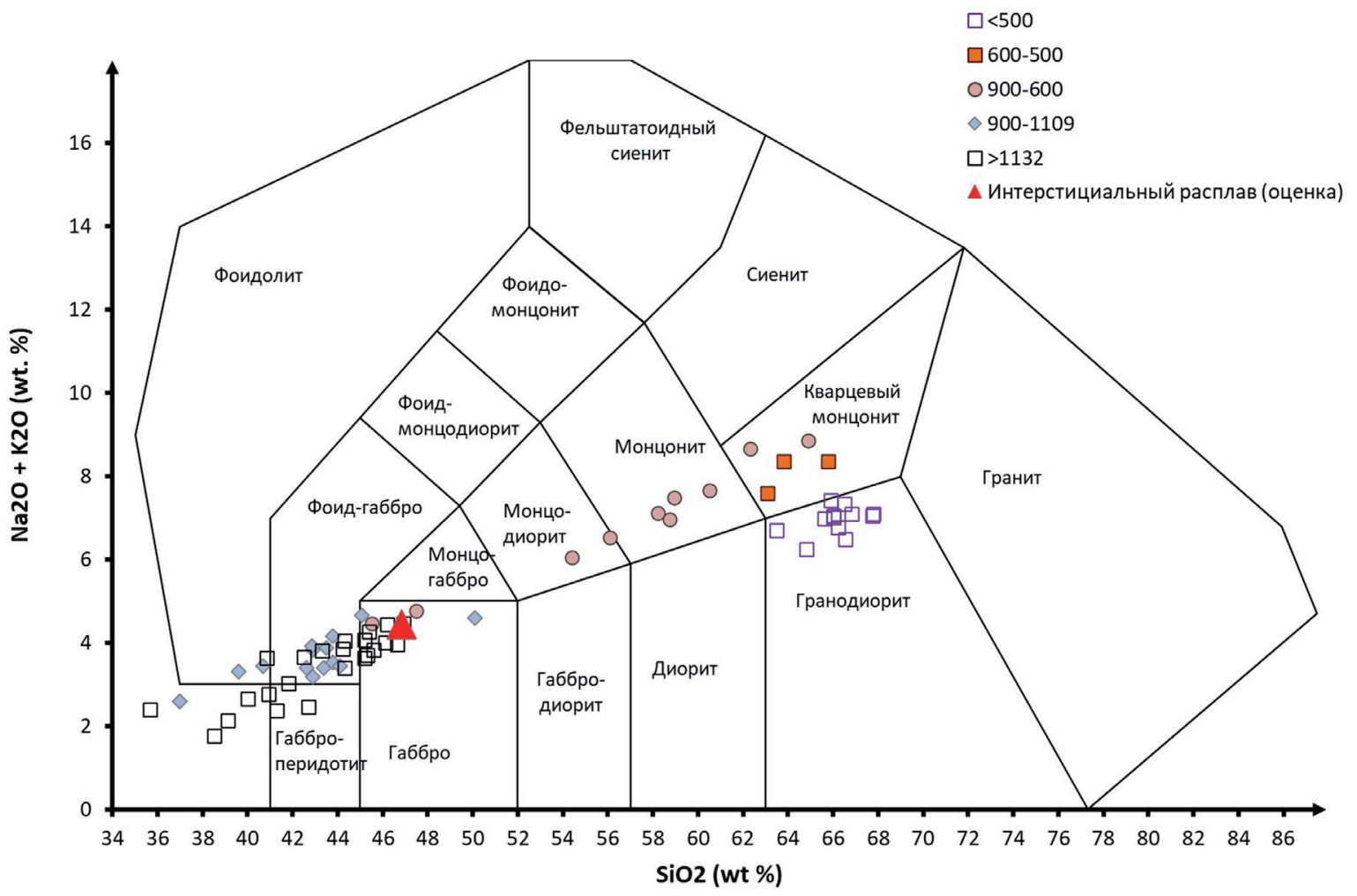

Рис. 1. Составы пород Контайской интрузии и оценка состава интерстициального расплава. Разными знаками показаны составы пород различных диапазонов вертикального разреза (цифры соответствуют глубине от устья скважины).

Fig. 1. TAS -diagram for Kontay intrusion rocks. Samples from intrusion zones of different depths are shown with different signs. The red triangle shows an estimated composition of the interstitial melt for the lower zone of intrusion.

\section{Методика исследования}

Изотопный состав $\mathrm{Sr}$ и $\mathrm{Nd}$ и концентрации $\mathrm{Rb}, \mathrm{Sr}, \mathrm{Sm}$ и $\mathrm{Nd}$ были измерены в ГИ КНЦ РАН по стандартной методике (Баянова, 2004). Погрешности определения изотопного состава (95\%-ный доверительный интервал) $\mathrm{Sr}$ не превышают $0.04 \%, \mathrm{Rb} / \mathrm{Sr}$ отношений - $1.2 \%$, изотопного состава $\mathrm{Nd}$ 
не превышают $0.03 \%, \mathrm{Nd} / \mathrm{Sm}$ отношений - $0.3 \%$. Расчёт параметров изохрон проводился по программе Isoplot-R (Vermeesch, 2018).

\section{Результаты их обсуждение}

$\mathrm{Rb}-\mathrm{Sr}$ изохрона, полученная для образца биотитового габбро (рис. 2) демонстрирует возраст $244.9 \pm 2.8$ млн. лет, что соответствует возрасту, определённому по цирконам.

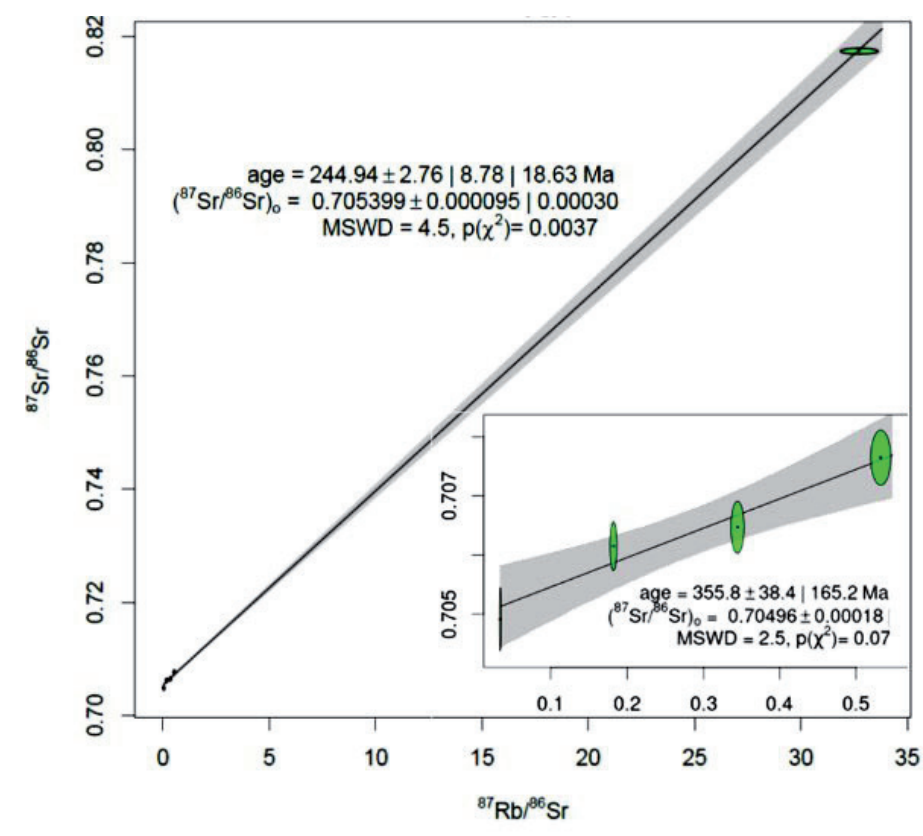

Рис. 2. Изохронная диаграмма для образца биотитового габбро.

Fig. 2. Isochron diagram for the biotite gabbro sample.

Этот возраст попадает на конец первого пульса внедрения Сибирских трапповых базальтов по (Ivanov et al., 2013), он совпадает возрастом меймечитов (Dalrymple et al., 1995) и временем отжига треков в апатите (AFT) Гулинской интрузии (Мышенкова и др., 2020) (рис. 3).

Следует отметить, что наклон изохроны, по существу, определяется положением фигуративной точки биотита, тогда как фракции других минералов лежат на прямой, соответствующей заметно более древнему возрасту: $355 \pm 38$ млн. лет. Ещё для двух образцов по минеральным фракциям были получены линии наклона $337.3 \pm 20.0$ и $473.8 \pm 22.1$ млн. лет, свидетельствующие о сохранении гетерогенности в минералах слагающих Контайскую интрузию пород. Для валовых проб по-

Рис. 3. Соотношение датировок Контайской интрузии с возрастами пород Сибирских траппов, датировками Гулинской интрузии и вулканитов Маймеча-Котуйской провинции (по Ivanov et al., 2013, Malich et al., 2015, Kamo et al., 2003, Kogarko and Zartman, 2007, Burgess, Bowring, 2015, Мышенкова и др., 2020).

Fig. 3. Age relations of the Kontay intrusion, Guli massif with lavas of the Siberian traps and Maimecha-Kotyu area (data from Ivanov et al., 2013, Malich et al., 2015, Kamo et al., 2003, Kogarko and Zartman, 2007, Burgess, Bowring, 2015, Мышенкова и др., 2020).

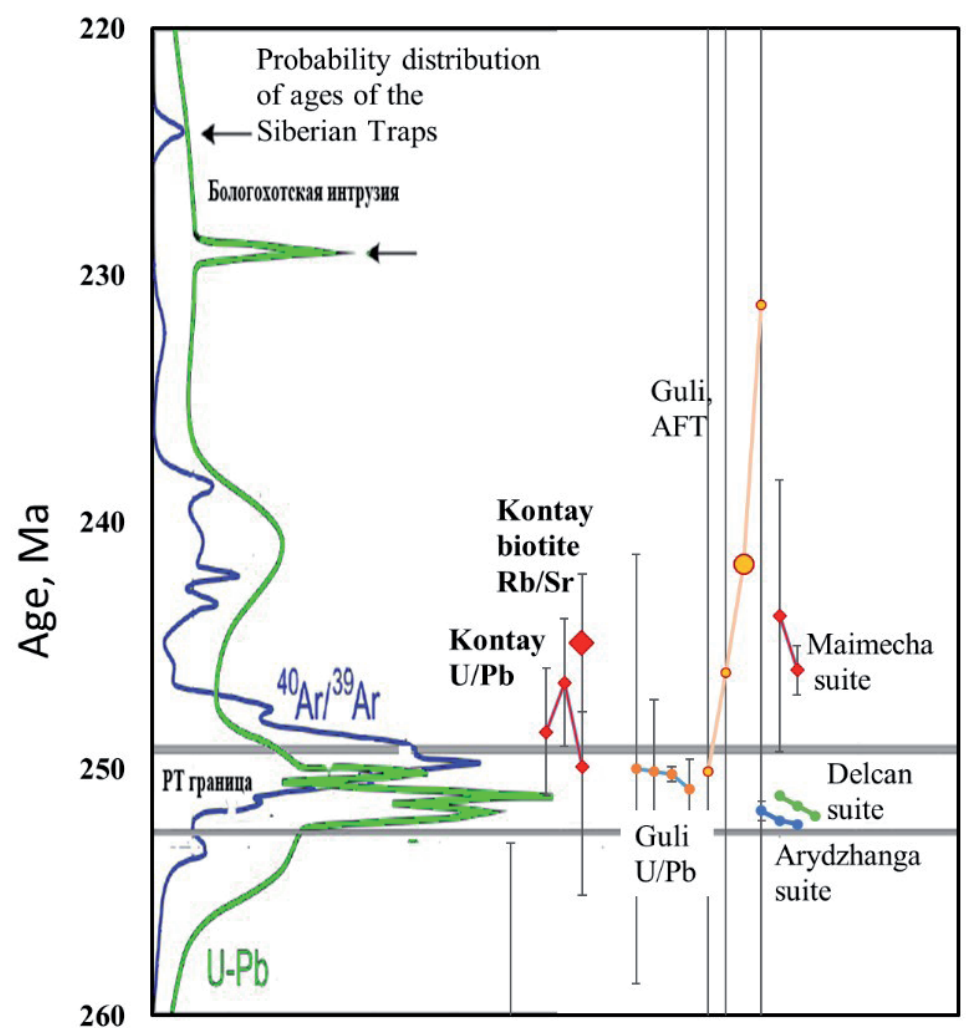




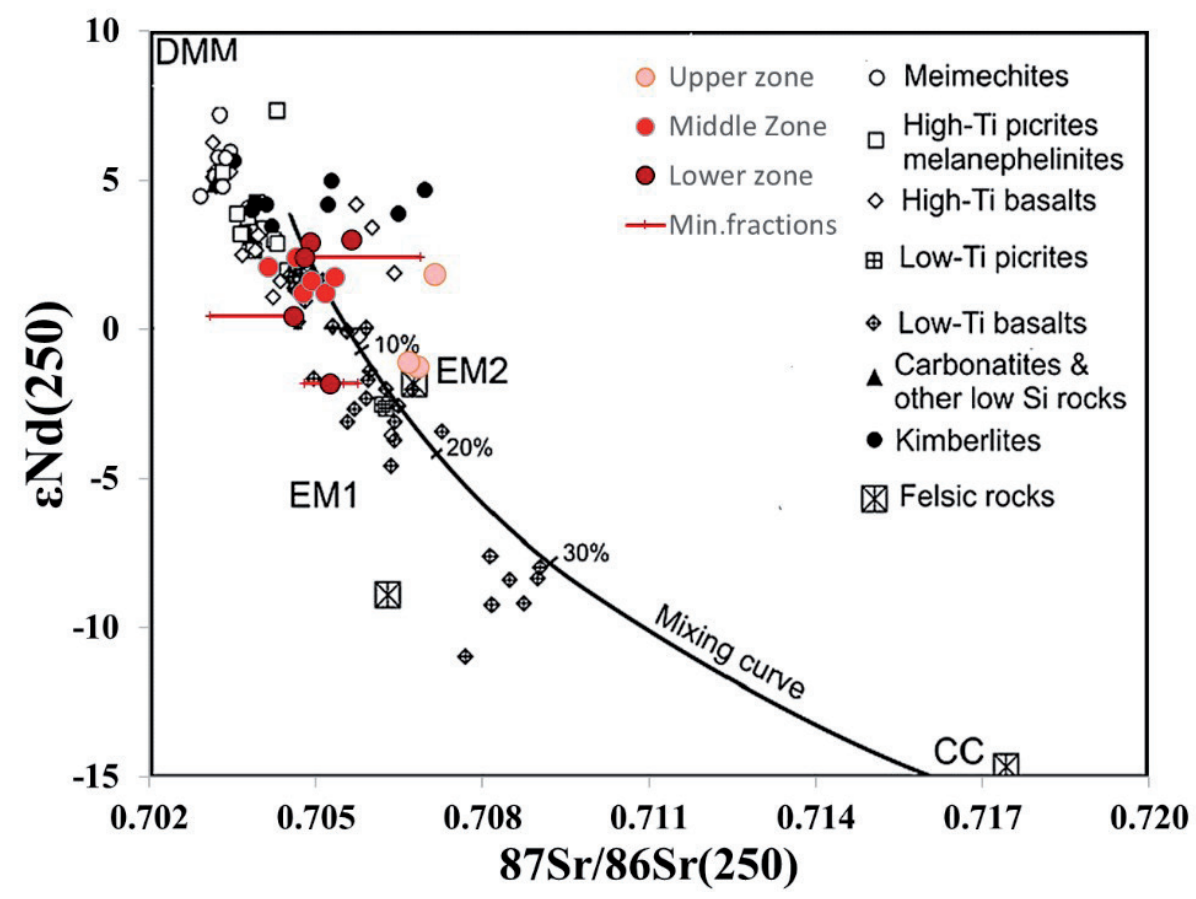

Рис. 4. Сопоставление вариаций изотопного состава пород Контайской интрузии с вариациями изотопного состава различных магм Сибирской трапповой провинции. Данные для эффузивов и линия смешения взяты из работы (Ivanov et al., 2018).

Fig. 4. $\varepsilon N d$ vs. ${ }^{87} \mathrm{Sr} /{ }^{86} \mathrm{Sr}$ diagram showing a plot of the Kontay intrusion rocks together with the published isotope compositions of Siberian trapps and Maimecha-Kotuy region effusive rocks. The data for effusive and the mixing line are taken from (Ivanov et al., 2018).

род из пород средней и нижней частей разреза, наклоны в $\mathrm{Rb} / \mathrm{Sr}$ и $\mathrm{Sm} / \mathrm{Nd}$ системах соответствуют возрастам $499.8 \pm 12$ скво $=6.2$ и $464.5 \pm 42.6$ скво $=13$.

Все эти «возрасты» не имеют геологически-логичной интерпретации и свидетельствуют, что на момент 225 млн. лет вещество интрузии было гетерогенно, как в масштабе пород, так и в масштабе слагающих их минералов.

Для того, чтобы сравнить изотопную гетерогенность массива с моделью смешения вещества из разных источников, происходившего на границе перми и триаса (Ivanov et al. 2018), изотопные данные были пересчитаны на возраст 250 млн. лет и представлены на диаграмме ${ }^{87} \mathrm{Sr} /{ }^{86} \mathrm{Sr}_{(250)}{ }^{\text {от }}$ $\varepsilon \mathrm{Nd}_{(250)}$ (рис. 4). Рассмотрение этой диаграммы показывает, что фигуративные точки пород занимают большую область, при этом наблюдается компактная группа, которую образует большинство точек пород нижней зоны и породы средней зоны, тогда как породы верхней зоны отклоняются от кривой смешения с коровым материалом - образец 1176 - в сторону обогащения радиогенным неодимом, а остальные - в сторону обогащения радиогенным стронцием, причём разница в изотопном составе в разных минералах одного образца сравнима с вариациями, наблюдаемыми между разными образцами.

Наблюдаемые закономерности вариаций изотопного состава $\mathrm{Sr}$ и $\mathrm{Nd}$ показывают, что в ходе дифференциации Контайской интрузии происходило смешение вещества нескольких источников, причём изотопная гетерогенность была не полностью стёрта не только для пород в целом, но и для минералов одной породы. Поскольку в породах нижней зоны интрузии наблюдается две популяции клинопироксена (Зайцев и др., 2018), можно предположить, что наблюдаемый контраст может быть связан с внедрением магмы, содержавшей ксенокристаллы, которые не были полностью переуравновешены с расплавом, что и определило изотопную гетерогенность пород интрузии.

Исследования выполнены в рамках темы НИР № 0137-2019-0014. 


\section{Литература}

1. Баянова Т.Б. Возраст реперных геологических комплексов Кольского региона и длительность процессов магматизма. СПб. Изд-во: Наука. 2004. 174 с.

2. Зайцев В.А., Елизаров Д.В., Бычкова Я.В., Сенин В.Г., Баянова Т.Б. Первые данные о геохимии и возрасте Контайской интрузии, Полярная Сибирь // Геохимия. 2018. № 3. С. 222-236. https://doi.org/10.7868/ S0016752518030020.

3. Кушнир Д.Г. Геологическое строение зоны сочленения Енисей-Хатангского регионального прогиба с Сибирской платформой в междуречье Хеты и Котуя по геофизическим данным. Дисс. на соискание ученой степени к.Г.-М.н. Екатеринбург. 2005. 154 с.

4. Липенков Г.В., Мащак М.С., Кириченко В.Т., Наумов М.В. и др. Государственная геологическая карта Российской Федерации. Масштаб $1: 1000000$ (третье поколение). Серия Норильская. Лист R-47 Хета. Объяснительная записка. СПб.: Картографическая фабрика ВСЕГЕИ. 2018. 464 с. +5 вкл.

5. Мышенкова М.С., Зайцев В.А., Томсон С., Латышев А.В., Захаров В.С., Багдасарян Т.Э., Веселовский Р.В. Термальная история Гулинского плутона (север Сибирской платформы) по результатам трекового датирования апатита и компьютерного моделирования // Геодинамика и тектонофизика. 2020;11(1):75-87. https://doi.org/10.5800/GT-2020-11-1-0464.

6. Bagdasaryan T., Veselovskiy R., Myshenkova M., Zaitsev V., Thomson S., Latyshev A. and Zakharov V.: New apatite fission track thermochronology data from the Siberian Permian-Triassic Traps, EGU General Assembly 2020. Online, 4-8 May 2020. EGU2020-692. https://doi.org/10.5194/egusphere-egu2020-692.

7. Burgess S.D., Bowring S.A. High-precision geochronology confirms voluminous magmatism before, during, and after Earth's most severe extinction // Sci. Adv. 2015. V. 1. Iss. 7. e1500470. https://oi.org/10.1126/ sciadv. 1500470 .

8. Dalrymple G.B., Czamanske G.K., Fedorenko V.A., Simonov O.N., Lanphere M.A., Likhachev A.P. A reconnaissance $40 \mathrm{Ar} / 39 \mathrm{Ar}$ geochronologic study of ore-bearing and related rocks, Siberian Russia. Geochim. Cosmochim. Acta 1995. V. 59. P. 2071-2083. https://doi.org/10.1016/016-7037(95)00127-1.

9. Ivanov A.V., Mukas S.B., Kamenetsky V.S., Ackersond M., Demonterova E.I., Pokrovsky B.G., Vladykin N.V., Kolesnichenko M.V., Litasov K.D., Zedgenizov D.A. Volatile concentrations in olivine-hosted melt inclusions from meimechite and melanephelinite lavas of the Siberian Traps Large Igneous Province: Evidence for fluxrelated high-Ti, high-Mg magmatism // Chemical Geology. V. 483. P. 442-462. https://doi.org/10.1016/j. chemgeo.2018.03.011.

10. Ivanov A.V., He H., Yan L., Ryabov V.V., Shevko A.Y., Palesskii S.V., Nikolaeva I.V. Siberian Traps large igneous province: Evidence for two flood basalt pulses around the Permo-Triassic boundary and in the Middle Triassic, and contemporaneous granitic magmatism. Earth Science Review. 2013. V. 122. P. 58-76. http://dx.doi.org/10.1016/j.earscirev.2013.04.001.

11. Kamo S.L., Czamanske G.K., Amelin Yu., Fedorenko V.A., Davis D.W., Trofimov V.R. Rapid eruption of Siberian flood-volcanic rocksand evidence for coincidence with the Permian-Triassic boundary andmass extinction at $251 \mathrm{Ma} / /$ Earth Planet. Sci. Lett. 2003. V. 214. P. 75-91.

12. Kogarko L.N., Zartman R.E. A Pb isotope investigation of the Gulimassif, Maymecha-Kotuy alkaline-ultramafic complex, Siberian floodbasalt province, Polar Siberia // Miner. Petrol. 2007. V. 89 (1-2). P. 113-132.

13. Malich K.N., Khiller V.V., Badanina I.Yu., Belousova E.A. Results of dating of thorianite and baddeleyite from carbonatites of the Guli massif, Russia // Doklady Earth Sciences 2015. V. 464 (2). P. 1029-1032. https://doi.org/10.1134/S1028334X15100050.

14. Vermeesch P. Isoplot R: a free and open toolbox for geochronology //Geoscience Frontiers. 2018. V. 9. P.1479-1493. https://doi.org/10.1016/j.gsf.2018.04.001. 